\section{Colloidal Fouling of Ultrafiltration MEMBRANES: IMPACT OF AGgREGATE STRUCTURE AND SIZE}

Journal of Colloid and Interface Science

Submitted, March 1998

Edited Version Resubmitted, December 1998

T. David Waite ${ }^{1}$, Andrea I. Schäfer ${ }^{2}$, Anthony G. Fane ${ }^{2}$ and Axel Heuer ${ }^{1}$

${ }^{1}$ School of Civil and Environmental Engineering, University of New South Wales, Sydney 2052, Australia

${ }^{2}$ UNESCO Centre for Membrane Science and Technology, School of Chemical Engineering and Industrial Chemistry, University of New South Wales, Sydney 2052, Australia

\section{ABSTRACT}

A close coupling between the structure and size of hematite flocs formed in suspension and the permeability of the cake that accumulates on ultrafiltration membranes is observed. Specific resistances of cakes formed from flocs generated under diffusion limited aggregation (DLA) conditions are at least an order of magnitude lower than cakes formed from flocs generated under reaction limited aggregation (RLA) conditions. Similar effects are observed whether the aggregation regime is controlled by sal concentration, $\mathrm{pH}$ or added organic anions. This dramatic difference in cake resistance is considered to arise from the size and fractal properties of the hematite assemblages. The ease of fluid flow through these primary particle size (since for fractal aggregates, porosity increases as the size of the aggregate increases). The size and strength of aggregates are also important determinants of the relative effects of permeation drag, shear induced diffusion and inertial lift and result, in the studies reported here, in relatively similar rates of particle deposition for both rapidly and slowly formed aggregates. The results presented here suggest that control of cake permeability (and mass) via control of aggregate size and structure is an area with scope for further development though the nature and extent of compaction effects in modifying the fractal properties of aggregates generated in suspension requires attention.

KEYWORDS: membrane filtration, ultrafiltration, fractal, aggregation, iron oxides, fulvic acids

* Author to whom correspondence should be addressed; tel: +61-2-9385 5060; fax: +61-2-9385 6139; email: d.waite@unsw.edu.au

\section{INTRODUCTION}

Ultrafiltration (UF) membranes exhibit pore sizes in the range of $2-100 \mathrm{~nm}$ and as such are able to remove viruses, bacteria, colloids and larger particulate matter from suspensions. In part because of their ability to produce a treated water free of pathogens, UF membrane use in treatment of waters and wastes is increasing but high capital and operating costs still remain a critical factor in limiting their more extensive application (1). Important factors in determining these costs are the magnitude of permeate flux that can be achieved and frequency of membrane cleaning.

The flux $\mathbf{J}$ of fluid across a membrane free of deposited materials may be described by Darcy's law:

$$
\mathrm{J}=\frac{\Delta \mathrm{P}}{\mu \mathrm{R}_{\mathrm{m}}}
$$

where $\Delta \mathrm{P}$ is the pressure drop across the membrane (the trans-membrane pressure drop, or TMP), $\mu$ is the absolute viscosity of the fluid and $\mathrm{R}_{\mathrm{m}}$ is the hydraulic resistance of the clean membrane with dimension of reciprocal length. Reductions in permeate flux may result from accumulation of materials i) within membrane pores as a result of adsorption or blocking processes, ii) at the membrane surface forming a gel and/or a porous "cake", and iii) near the membrane surface in the concentration boundary (the so-called concentration-polarization) layer (2). While the size reduction or blockage of pores may be considered to increase the resistance of the membrane ( $\left.\mathrm{R}_{\mathrm{n}}\right)$ mbrane $\left(R_{m}\right)$ called "polarised" solids) presents additional resistances to permeation (denoted here as $\mathrm{R}_{\mathrm{c}}$ and $\mathrm{R}_{\mathrm{cp}}$ respectively). These resistances vary as a function of the composition and thickness of each layer, which in turn are determined by the feed water quality and the characteristics of mass transfer in the membrane module. In most instances encountered in water and wastewater treatment, it appears that the concentration-polarization layer, if it is formed, contributes negligible resistance to permeate flux; i.e. $R_{c p}<<R_{c}$ and, therefore, $R_{c p}$ may be neglected (2). The flux through a UF membrane containing a deposited layer may thus be written

$$
\mathrm{J}=\frac{\Delta \mathrm{P}}{\mu\left(\mathrm{R}_{\mathrm{m}}+\mathrm{R}_{\mathrm{c}}\right)}
$$

According to filtration theory (3), the resistance of cake solids (assuming solids in the concentration-polarisation layer to be negligible) can be written as

$$
\mathrm{R}_{\mathrm{c}}=\alpha \frac{\mathrm{m}_{\mathrm{p}}}{\mathrm{A}_{\mathrm{m}}}
$$

where $m_{p}$ is the mass of deposited particles, $A_{m}$ the membrane area and $\alpha$ the specific resistance of the deposit, which can be approximated for cakes formed from uniform, spherical particles by the Carman-Kozeny relationship (4)

$$
\alpha=\frac{180(1-\varepsilon)}{\rho_{\mathrm{p}} \mathrm{d}_{\mathrm{p}}^{2} \varepsilon^{3}}
$$

where $\varepsilon$ is the void volume of the cake, $\rho_{\mathrm{p}}$ the density of the particles and $\mathrm{d}_{\mathrm{p}}$ is the mean diameter of the particles. For such a cake, the resistance would thus be expected to increase in proportion to the cake mass and as the inverse of the square of the primary particle size. A strong dependence on cake porosity is also predicted; for example, a change in $\varepsilon$ from 0.2 to 0.1 would be expected to induce a 10 -fold increase in $\alpha$. 
The Carman-Kozeny relationship is recognized to be valid for media with porosities less than 0.5 (5). As such, this semi-empirical expression is well suited to description of the permeability of relatively compact cakes formed by deposition in non-aggregating systems where the particles would be expected to pack uniformly on the membrane surface. More porous cakes are commonly formed when particles agregate prior to deposition on the membrane surface. Whilst corrections to the Kozeny relationship for high porosity cakes have been deduced (6), these apply to fibres and "ring packing's" and their applicability to aggregrates has not been tested. Aggregates are now recognized to exhibit fractal properties (7) and, as such, may be expected to form membrane cakes of somewhat different behavior to a cake formed from non-aggregated particles. One implication of the fractal nature of particulate aggregates is that the porosity of the aggregate $\left(\varepsilon_{a}\right)$ is not spatially uniform but increases as the radius of the aggregate $(r)$ increases according to the relationship $(8$,

$$
\varepsilon_{\mathrm{a}}=1-\rho=1-\left(\frac{\mathrm{r}}{\mathrm{a}_{\mathrm{p}}}\right)^{\mathrm{D}-3}
$$

where $\mathrm{a}_{\mathrm{p}}$ is the radius of the primary particle and $\rho$ is the density and $\mathrm{D}$ is the fractal dimension of the aggregate (note: $\mathrm{D}=3$ for a solid sphere, 2 for a solid sheet and 1 for a line). Such behavior is certain to influence the permeability of the cake and suggests that factors such as fractal dimension coupled with aggregate size will be important determinants of cake properties.

An exciting development is that, through investigations over the last ten years, a close association between aggregation conditions and the fractal properties of the resulting aggregate are now recognized and reasonably well understood (10-12). While issues such as aggregate restructuring and compression on cake formation must be addressed, this relationship between aggregation conditions and resulting aggregate structure opens the way to design of cake properties through control of suspension conditions.

Many investigators have recognized the importance of aggregation conditions either in suspension or at the membrane surface to cake properties (13-23). Indeed, some workers have recently suggested that the fractal properties of aggregates formed may be influencing membrane filtration behavior (24). No studies however have been undertaken where the fractal properties of aggregates formed are carefully controlled and the implications to membrane filtration investigated. In this study, we prepare aggregates of well-characterized hematite under carefully controlled suspension conditions similar to those used in previous investigations (25-27) and examine the impact of the conditions similar to those used in previous investigations (25-27) and examine the impact of the
resulting cakes formed on permeate flux through ultrafiltration (UF) membranes of sufficiently small pore size that pore clogging effects are minimized. Given our interest in application of UF membranes in water treatment, attention is focussed on the effects of ionic strength, $\mathrm{pH}$ and the presence of adsorbing natural organic acids on aggregate structure and thence ultrafiltration behavior.

\section{MATERIAL AND METHODS}

Membranes. The ultrafiltration membranes used in this study were hydrophilic regenerated cellulose membranes manufactured by Millipore (Bedford, USA) with a molecular weight cut off of $100 \mathrm{kDa}$ and a zeta potential (as determined by streaming potential measurement) reducing linearly from -2 to $-6 \mathrm{mV}$ over the $\mathrm{pH}$ range 3 to 6 . The supporting material of the asymmetric membranes was polypropylene. Prior to use, the membranes were soaked in $0.1 \mathrm{M} \mathrm{NaOH}$ for 30 minutes and flushed with $3.4 \mathrm{~L}$ of Milli-Q water in order to remove the preservative glycerin.
Chemicals. All reagents used in this study $\left(\mathrm{KCl}, \mathrm{CaCl}_{2}, \mathrm{NaCl}, \mathrm{NaOH}\right)$ were of analytical grade from Ajax Chemicals, Australia. Aqueous solutions were prepared using Milli-Q water with a specific resistance greater than $18 \mathrm{M} \Omega \cdot \mathrm{cm}^{-1}$. $\mathrm{pH}$ adjustments were made by adding either $1 \mathrm{~N}$ sodium hydroxide solution or $1 \mathrm{~N}$ hydrochloric acid.

Hematite $\left(\alpha-\mathrm{Fe}_{2} \mathrm{O}_{3}\right)$ particles were prepared after the method described by Matijevic and Scheiner (28) and exhibited a mean particle diameter from TEM analysis of approximately $70 \mathrm{~nm}$. The mean hydrodynamic diameter of hematite suspensions prior to aggregation was on the order of $100 \mathrm{~nm}$, suggesting the presence of some dimers and trimers in the stock suspension. Hematite suspensions were equilibrated at various defined $\mathrm{pH}$, salt and fulvic acid concentrations for 17 hours with stirring at $220 \mathrm{rpm}$ prior to membrane filtration.

Well-characterized Suwannee River fulvic acid was obtained from the International Humic Substances Society (IHSS) (29). A $1000 \mathrm{mg} / \mathrm{L}$ stock solution was prepared by dissolving the freeze dried fulvic acid powder in Milli-Q water and stored in darkness at $4^{\circ} \mathrm{C}$.

Particle characterization. Particle size measurements for particles and/or aggregates smaller than $1 \mu \mathrm{m}$ were performed on a Malvern Photon Correlation Spectrometer (PCS) Autosizer 4700 (5 mW, He-Ne laser). Size distribution of agregates larger than 1 micron were analyzed by using a Malvern Mastersizer E equipped with a $100 \mathrm{~mm}$ lens. Since the aggregation process is a function of time, samples of the feed suspension were taken prior to the ultrafiltration experiments and immediately analyzed with the Malvern Mastersizer.

The structure of hematite aggregates prepared in a manner identical to that used here (i.e. identical $\mathrm{pH}$, temperature and ionic strength conditons) has previously been determined whilst the aggregates were still in the colloidal (sub-micron) size range by measuring the scattered light intensity at angles ranging from $15^{\circ}$ to $90^{\circ}$ using the Malvern 4700 (which was equipped with a goniometer). Data was accumulated at each angle for a 5 second period prior to moving to the next angle and was performed when the rate of change in mean aggregate size was slow $(25,26)$. Conventional analysis of the static light scattering results so obtained yielded mass fractal dimensions that provided insigh into the nature of packing within the aggregates $(30,31)$. For the larger sized aggregates that were present after overnight equilibration, a static light scattering approach was also used for structure analysis but it was necessary to determine light intensity at much smalle for the colloidal systems. This was achieved using the Malvern Mastersizer/E which contains 31 light sensitive diodes over scattering angles of 0.03 to $6.25^{\circ}$. Jung et al. (32) have shown that this technique produces reliable structural information for aggregates of monodisperse particles in an appropriate size range.

A Coulter DELSA 440 Zeta Sizer was used to measure the zeta potential of particles in aqueous suspensions. The sample suspensions were equilibrated for at least 12 hours at defined ionic strength, $\mathrm{pH}$ or organic concentration before the hematite aggregates were redispersed by ultrasonification for $10 \mathrm{~min}$ and finally the zeta potential measurement was conducted.

Chemical analyses. Total Organic Carbon (TOC) measurements were performed on an SK 12 TOC Analyser from Skalar (The Netherlands).

The total iron concentration was measured with a Varian atomic absorption spectrometer SpectrAA10. The hematite particles were dissolved in $4 \mathrm{M} \mathrm{HCl}$ prior to atomic absorption analysis. The $\mathrm{pH}$ measurements were made on a Beckman $\Phi 50 \mathrm{pH}$ meter with an Activon AEP31 Ag/AgCl electrode. The $\mathrm{pH}$ meter was calibrated using standards provided by Activon. 
Stirred batch-cell system. All ultrafiltration experiments were performed in a Perspex batch-cell of $110 \mathrm{~mL}$ capacity consisting of a cylindrical section and two circular end pieces. The top endpiece contained a feed inlet and a pressure relief valve while the bottom of the cell contained porous insert which supports a $15.2 \mathrm{~cm}^{2}$ membrane. The cell housed an internal magnetic stimer bar (35 mm long, 7 m dion (35 min long, 7 mm dion induced by a magnetic stirrer table placed underneath the batch-cell. The feed solution was continuously introduced from one or two cylindrical reservoirs of $1700 \mathrm{~mL}$ capacity which were connected to the batch-cell. The reservoir was pressurized using nitrogen gas.

The experiments were conducted with transmembrane pressures in the range of 0 to $300 \mathrm{kPa}$ and a temperature of $25^{\circ} \mathrm{C}$. The stirring speed in most experiments was set to $520 \mathrm{rpm}$ (measured with

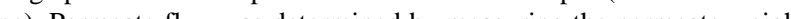
with a Sartorius U5000 elect with a Sartius accumulated was determined under selected suspension conditions in separate runs and involved cessation of the experiment after passage of a known volume of permeate, careful removal of the liquid above the cake an determination of the cake mass. The cake mass was measured by separating the membrane skin and accumulated cake from the membrane support after drying for $1.5 \mathrm{~h}$ at $80^{\circ} \mathrm{C}$ and weighed. The weight of the clean membrane skin was determined to be $17.5 \pm 0.2 \mathrm{mg}$.

\section{RESULTS}

\section{Aggregate Characteristics}

Aggregation kinetics. Both the results of earlier studies of the aggregation kinetics of hematite (26, 33) and the results obtained here indicate that the $70 \mathrm{~nm}$ diameter primary particles of hematite aggregated in the presence of both low (e.g. $20 \mathrm{mM}$ ) and high concentrations (e.g. $100 \mathrm{mM}$ ) of $\mathrm{KCl}$ though aggregation was significantly slower at the lower salt concentrations as a result of the presence of significant interparticle repulsion barriers. Double layer compression on increasing the counter-ion (chloride) concentration resulted in significant increases in aggregation rate with diffusion limited rates (in the colloidal regime) being attained at $\mathrm{KCl}$ concentrations of around 60 $\mathrm{mM}$ and $\mathrm{CaCl}_{2}$ concentrations of approximately $30 \mathrm{mM}$. As shown previously $(25,33)$, diffusion limited aggregation could also be induced by lowering surface charge through either $\mathrm{pH}$ increase or addition of an organic anion (fulvic acid) which adsorbed to the colloid surface. Once either the $\mathrm{pH}_{\mathrm{pcc}}$ had been passed or sufficient fulvic acid had been added to reverse the surface charge, reaction limited (slow) aggregation was again observed. Obviously, once the aggregates grew to sizes significantly in excess of one micron, the kinetics of aggregation became influenced by the mixing regime prevailing in the reaction vessel (orthokinetic coagulation).

Aggregate size. Size distributions typical of aggregates formed under low and high salt concentrations either side of the critical coagulation concentrations (c.c.c.) are shown in Figures 1a and $1 \mathrm{~b}$ respectively. Interestingly, two peaks were consistently observed in the size distributions for aggregates formed under reaction limited (low salt) conditions with one grouping of aggregates in the $0.1-1.0 \mu \mathrm{m}$ size range and another grouping in the $20-100 \mu \mathrm{m}$ range. This latter group of aggregates typically exhibited a mode size in the volume-based size distribution of around $30-50$ $\mu \mathrm{m}$. In comparison, aggregates formed at salt concentrations greater than the c.c.c. exhibited only one major peak in the volume-based size distribution with mode sizes typically around $8-10 \mu \mathrm{m}$.

Aggregate structure. Results of previous static light scattering studies on colloidal hematite aggregates formed under conditions identical to those used here $(25,26)$ revealed two distinct structural regimes. Under reaction limited aggregation (RLA) conditions, relatively compact aggregates were obtained while under diffusion limited aggregation (DLA) conditions, somewhat more open particle assemblages were observed. This association of aggregate structure and aggregation kinetics has now been widely reported for a range of colloidal systems (11). Fracta dimensions of $1.83 \pm 0.07$ and $2.2 \pm 0.1$ determined using static light scattering by Zhang and Buffle (26) for hematite aggregates prepared under DLA and RLA conditions respectively are consistent with those reported for other colloidal systems $(7,34)$

The results of small angle light scattering studies of the same set of aggregates generated under low and high salt $(\mathrm{KCl})$ concentrations as described in Figure 1 are shown in Figure 2. These results are consistent with the size distribution data with scattering from two distributions of particles evident in the $10 \mathrm{mM} \mathrm{KCl}$ results and from one distribution at $100 \mathrm{mM} \mathrm{KCl}$. The scattering data in the 10 $\mathrm{mM} \mathrm{KCl}$ case at low wavenumber $(\mathrm{q})$ is attributable to the larger sized cohort of particles (larger $\mathrm{mM} \mathrm{KCl}$ case at low wavenumber $(\mathrm{q})$ is attributable to the larger sized cohort of particles (larger
particles scatter light both more intensely and at smaller angles than do smaller particles) while the low intensity contribution at high $\mathrm{q}$ is attributable to the cohort in the sub-micron size range. While power law scattering is evident in both low and high salt concentration cases (confirming the presence of fractal structure), extraction of definitive structural information is non-trivial given the complexity of these systems. Thus, for the $10 \mathrm{mM} \mathrm{KCl}$ case, a linear region in the log I vs. $\log q$ plot can be defined and provides a scattering exponent of $2.35 \pm 0.02$, however the choice of data points is rather subjective given the presence of the high q contribution. Similarly, in the $100 \mathrm{mM}$ $\mathrm{KCl}$ case, a linear region can be defined and a scattering exponent of $2.20 \pm 0.01$ obtained but 
departure from linearity occurs at high q (where the slope of the log I vs. log q plot approaches 1.8), again rendering the choice of data points somewhat subjective.

\section{Membrane filtration}

Effect of ionic strength. The effect of suspension $\mathrm{KCl}$ concentration on permeate flux is shown in Figure 3 (with all initial feed fluxes given in Table 1). Two different flux regimes are observed. For $\mathrm{KCl}$ concentrations between 0 and $60 \mathrm{mM}$, rapid flux decline is seen with the flux decreasing to less than $50 \%$ of the initial flux after passage of $2.8 \mathrm{~L}$ of permeate. A remarkably similar pattern of flux decline is observed for salt concentrations of 0,20 , and $60 \mathrm{mM} \mathrm{KCl}$. In comparison very little flux decline is observed for 70 and $100 \mathrm{mM} \mathrm{KCl}$.

The effect of the $\mathrm{KCl}$ concentration on the cake resistance after filtration of $2.8 \mathrm{~L}$ feed suspension is presented in Figure 4. The calculation of the resistance is based on the "resistance in series" model presented in Eq. [2]. Since the single particles with a mean diameter of $70 \mathrm{~nm}$ are too large to penetrate the membrane pores which have an estimated pore size of less than $10 \mathrm{~nm}$ (35), separation of the total resistance into the intrinsic membrane resistance and the resistance due to the hydraulic resistance of the filtration cake would seem reasonable. A high hydraulic cake resistance is observed for concentrations between 0 and $60 \mathrm{mM} \mathrm{KCl}$ and a lower hydraulic resistance for concentrations higher than $70 \mathrm{mM}$. A distinct break between these two regimes is observed at around $65 \mathrm{mM} \mathrm{KCl}$.

As can be seen from Figure 5, relatively similar cake masses are observed for $\mathrm{KCl}$ concentrations either side of the critical coagulation concentration, at least for the first litre of permeate filtered. A slightly lower cake mass is evident at larger permeate volumes for the high salt compared to the low salt concentration case. These cake masses have been used to obtain the specific cake resistances $(\alpha$ in Eq. [3]) shown in Table 2 for permeate volumes of 1.0, 1.5 and 2.0 L. Averaging of values obtained at these three permeate volumes yields specific cake resistances of $(1.18 \pm 0.09) \times 10^{10}$ $\mathrm{m} . \mathrm{g}^{-1}$ and $(0.092 \pm 0.011) \times 10^{10} \mathrm{~m} \cdot \mathrm{g}^{-1}$ for $20 \mathrm{mM}$ and $100 \mathrm{mM} \mathrm{KCl}$ respectively. The value of $1.18 \times 10^{10} \mathrm{~m} \cdot \mathrm{g}^{-1}$ is close to the specific resistance calculated using the Carman-Kozeny equation

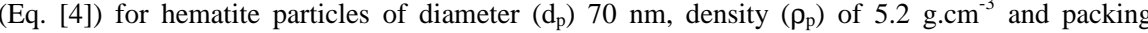
density of 0.4 , i.e. only slightly less compact than that arising from random close packed spheres for which $1-\varepsilon=0.63$

A similar dramatic effect of salt concentration is observed when using $\mathrm{CaCl}_{2}$. As can be seen from Figure 6, two different flux regimes are again observed. Concentrations of 0 and $20 \mathrm{mM}$ cause rapid flux decline during the ultrafiltration with consistent fouling behavior. Little flux decline is found for $\mathrm{CaCl}_{2}$ concentration higher than $40 \mathrm{mM}$. As for the higher $\mathrm{KCl}$ concentrations, concentrations of 40,60 and $80 \mathrm{mM} \mathrm{CaCl}_{2}$ show a remarkably similar flux decline.

The effect of different $\mathrm{CaCl}_{2}$ concentrations in the feed suspension on the cake resistance after filtration of $2.8 \mathrm{~L}$ feed suspension can be seen in Figure 7. A high hydraulic cake resistance is evident for $\mathrm{CaCl}_{2}$ concentrations of 0 to $20 \mathrm{mM}$ and low hydraulic resistance for concentrations greater than $40 \mathrm{mM}$.

Effect of suspension $\mathbf{p H}$. While change in salt concentration is effective in inducing change in height of the inter-particle repulsion barrier and thus rate of aggregation, change in suspension $\mathrm{pH}$ will alter the hematite zeta potential and may thus also be used to control the rate of hematite will alter the hematite zeta potential and may thus also be used to control the rate of hematite
aggregation (and thus the structure of the resulting flocs). The zeta potential of hematite particles identical to those used in this study has been examined by both acid-base titration and mobility measurements (36) and found to decrease relatively linearly between $\mathrm{pH} 3$ and 12 with a point of zero charge around $\mathrm{pH} 9$. The implications of the $\mathrm{pH}$ dependence of zeta potential to aggregation kinetics has been investigated by Amal (36) who reported that, at low salt concentrations, diffusion limited aggregation could only be induced at around $\mathrm{pH} 9$ (in accord with the low interparticle repulsion barrier at this $\mathrm{pH}$ ). In accord with the recognised effect of salt in reducing the electrostatic repulsion at larger interparticle distances through double layer compression, rapid (transport limited) aggregation could be extended to a wider range of $\mathrm{pH}$ around the isoelectric point by increasing the salt concentration. Thus, while slow (reaction limited) aggregation was maintained at $\mathrm{pH} 3$, rapid (diffusion limited) aggregation could be induced at $\mathrm{pH} 5.5$ and 11.5 by increasing the $\mathrm{KCl}$ concentration to $40 \mathrm{mM}$ (36)

Co-incident with the effect of $\mathrm{pH}$ on hematite aggregation kinetics, we observe significant flux decline on ultrafiltration of hematite aggregates formed (and filtered) in $40 \mathrm{mM} \mathrm{KCl}$ at $\mathrm{pH} 3$ (slow aggregation) but significantly less flux decline on filtration of aggregates formed at $\mathrm{pH} 5.6,7.5$ and 10.5 (again, in $40 \mathrm{mM} \mathrm{KCl}$ ) where rapid aggregation has been observed (Figure 8).

Effect of fulvic acid. As can be seen from the permeation velocity data presented in Figure 9, the presence of the naturally occurring fulvic acid, and the variation of its concentration over a relatively narrow range, has a dramatic impact on permeate throughput in the presence of hematite. In the absence of fulvic acid and at a salt concentration $([\mathrm{KCl}]=40 \mathrm{mM})$ below the critical In the absence of fulvic acid and at a salt concentration $([\mathrm{KCl}]=40 \mathrm{mM})$ below the critical
coagulation concentration of hematite (at $\mathrm{pH} 3)$, significant flux decline occurs over the course of coagulation concentration of hematite (at $\mathrm{pH} 3$ ), significant flux decline occurs over the course of
the study with $\mathrm{J} / \mathrm{J}_{\mathrm{O}}$ reduced to 0.5 after passage of about $2.5 \mathrm{~L}$ of permeate In the presence of just 1 $\mathrm{mg} / \mathrm{L}$ of fulvic acid, the flux decline is substantially reduced with $\mathrm{J} / \mathrm{J}_{\mathrm{o}}$ dropping to only 0.8 on filtration of $2.5 \mathrm{~L}$ of solution. Slightly greater fouling is evident for $2 \mathrm{mg} / \mathrm{L}$ fulvic acid and use of 5 and $10 \mathrm{mg} / \mathrm{L}$ fulvic acid produces permeation velocities that are substantially lower than the no organic case $\left(\mathrm{J} / \mathrm{J}_{\mathrm{O}}\right.$ dropping to 0.4 and lower after filtration of $\left.2.5 \mathrm{~L}\right)$. In the presence of $10 \mathrm{mg} / \mathrm{L}$ $\mathrm{pH} 3$ buffered fulvic acid alone, a slightly lower extent of reduction in permeation velocity over the course of filtering $1.4 \mathrm{~L}$ of fluid than that found in the presence of rapidly aggregated particles (i.e. minimal fouling) was observed.

These membrane filtration results are presumably again correlated with the different aggregation behaviour of the hematite colloids for different concentrations of fulvic acid. Indeed, as shown in Figure 10, the cake resistance is at a minimum at the fulvic acid concentration (approximately 1 mg. $\mathrm{L}^{-1}$ ) where the zeta potential of the hematite particles is close to zero and where rapid aggregation has previously been observed to occur (37). At fulvic acid concentrations either side of this critical concentration, aggregation has been seen to be retarded due to the presence of high residual surface charge.

\section{DISCUSSION}

\section{Aggregate Characteristics}

The size distribution results obtained for hematite aggregates coagulated under diffusion limited and reaction limited aggregation conditions are of considerable interest in their own right but, due to space limitations, are only considered briefly here. In essence, it appears (as would be expected from investigations of floc strength vs. floc break-up studies by other workers (38)) that the more surface potential) are more prone to breakup, most likely through floc fragmentation or splitting. Indeed, the mode size of $8-10 \mu \mathrm{m}$ attained is in the same size range as that estimated for the Kolmogoroff microscale in the peak energy dissipation region (within the vicinity of the radial jet) in the stirred cylindrical membrane filtration chamber (39-41). The steady state size distribution observed is quite narrow in accord with previously reported effects of shear-induced fragmentation 
(42). In comparison, a portion of the aggregates generated under RLA conditions are of significantly larger size than the DLA aggregates presumably because their more compact structure is less prone to fragmentation. It should be noted that while there are some large aggregates present under RLA conditions (indeed, enough to contribute to more than half the volume of solids present), a large , These aggregates have presumably formed num effects. Only the larger aggregates in this size range will begin to experience the effects of mixing and be induced to grow to large size. These larger aggregates will also experience the dis-aggregative effects of mixing bu possibly through surface-erosion and loss of individual particles or small groupings of particles rather than the floc splitting that appears to be operative for flocs generated rapidly (43). The absence of intermediate-sized aggregates is supportive of such a mechanism.

While the implications of the aggregation regime (i.e. reaction or diffusion limited) to the eventua size distribution(s) attained in the stirred ultrafiltration cell are reasonably clear, the implications of aggregation kinetics in the colloidal size range to the structure of the eventual distribution of aggregates is less certain. Our major tool for structure determination is small angle light scattering but as stated earlier, the results in the supra-colloidal region are far from simple. Thus, while interpretation of the small angle light scattering results should not be taken too far given the uncertainties present, the results are suggestive of maintenance of the structural regimes developed 列 modifications due to mixing-induced restructuring. Jung et al. (32) have previously reported an increase in scattering exponent from 1.73 to 2.23 for an identical hematite suspension induced to aggregate at diffusion controlled rates in a stirred cell. Restructuring effects have been reported by Oles (44) and Lin et al. (7) have reported a similar departure in linearity in $\log$ I vs. $\log$ q plots to that observed in Figure 2 for the $100 \mathrm{mM} \mathrm{KCl}$ aggregates and attributed the result to a compaction at large scale (small q) where shear effects are significant but maintenance of looser structure at small length scales (high q) where the aggregates are strong enough to withstand the shear imposed. Thus, a difference in scattering exponents between hematite aggregates formed under low and high salt conditions of 2.35 and 2.20 (or even 1.8 if considering the high q region) respectively could be claimed as indicative of compact and less compact assemblages in each case but caution must be exercised in drawing such conclusions given the subjectiveness of the data analysis.

\section{Membrane Filtration}

It is reasonably apparent from the results presented earlier that minimal flux decline is observed when filtering hematite particles that have been induced to aggregate quickly (by salt addition, adjustment of $\mathrm{pH}$ or adsorbing ion addition) compared to the significant decline in permeate flux that is observed when filtering hematite particles that have been induced to aggregate slowly. That coagulation of colloidal suspensions affects the extent of membrane fouling has been well documented (16-24) with a variety of factors shown (or proposed) to account for the observed effects of coagulation on membrane flux. Thus, Kim et al. (18) found that aggregation of silver particles lowered the extent of fouling of ultrafiltration membranes and concluded that nonaggregated silver particles caused significant flux decline because of pore blocking by the individual particles whereas aggregation retained the particles in a surface cake. Such a mechanism is not likely to be of importance here since the primary hematite particles are significantly larger (approx $70 \mathrm{~nm}$ in diameter) than the membrane pores (approx. $10 \mathrm{~nm}$ in diameter) and would not be expected to penetrate the membrane in either the aggregated or (particularly) the non-aggregated states.

Coagulation has also been suggested to lead to a reduction in cake thickness (i.e. lowered fouling) as a result of generation of larger particles that are more susceptible to shear-induced diffusion and (for larger particles) inertial lift $(16,45,46)$. Indeed, a number of authors have satisfactorily modelled the reduction in extent of fouling as a result of the lowered cake mass arising from occurrence of these back-transport processes $(19,21)$. At the high permeation velocities occurring in the studies reported here $\left(10^{-1}-10^{-2} \mathrm{~cm} / \mathrm{s}\right)$, shear-induced diffusion and (particularly) inertial lift effects would be expected to only have an influence on aggregates of size greater than a few microns in diameter with increasing effect at larger aggregate sizes (46). It would appear from Figure 5 however, that these back-transport effects, while undoubtedly retarding deposition of the larger aggregates, are not exerting a dominant influence in the studies reported here. Relatively similar cake masses are seen to accumulate for both slowly and rapidly aggregated systems, particularly through passage of the first $1000 \mathrm{~mL}$ of permeate. A reduction in rate of cake accumulation is observed in both cases at higher permeate volumes and may reflect the increasing impact of inertial lift as permeate flux drops in response to increasing cake thickness. The slightly lower rate of accumulation of hematite flocs on the membrane in the case of rapid agregation (compared to aggregates generated more slowly) may result from the fact that almost all of the rapidly formed aggregates are of a size $(3-10 \mu \mathrm{m})$ that might be expected to experience some impact of back-transport processes (particularly shear induced diffusion) while only a portion of the more slowly formed aggregates (i.e. those in the larger sized cohort) would be expected to experience the impact of inertial lift

Given that neither a pore blocking mechanism nor a reduced cake thickness due to aggregate backtransport can account for the observed differences in flux for cakes formed from rapidly-formed compared to slowly-formed aggregates, we must conclude that the differences in permeation compared to slowly-formed aggregates, we must conclude that the differences in permeation
velocity arise from differences in permeability of the cakes formed under the different aggregation velocity arise from differences in permeability of the cakes formed under the different aggregation regimes. The order of magnitude difference in specific resistances of cakes developed at $20 \mathrm{mM}$ and
$100 \mathrm{mM} \mathrm{KCl}$ concentrations (approx. $1 \times 10^{10} \mathrm{~m} \cdot \mathrm{g}^{-1}$ versus approx. $0.1 \times 10^{10} \mathrm{~m}_{\mathrm{g}} \mathrm{g}^{-1}$ respectively) supports the contention that the cakes formed under different aggregation regimes have fundamentally different permeabilities. Given that coagulation occurs at both low (less than the c.c.c.) and high (above c.c.) salt concentrations, simple particle/agrregate size arguments (and the concomitant effects on cake porosity) would seem insufficient to account for the observed behaviour.

A possible approach is to consider that the fractal properties of the suspended aggregates are retained (to some extent) by the filter cake. While further consideration must be given to compaction effects, aggregate structure characteristics can be incorporated into the Carman-Kozeny equation $\left(\alpha \propto(1-\varepsilon) / \varepsilon^{3}\right)$ using Eq. [5] $\left(\varepsilon=1-\left(\mathrm{r} / \mathrm{a}_{\mathrm{p}}\right)^{\mathrm{D}}\right)$. The ratio of specific resistances expected for hematite cakes made up of aggregates of various sizes $\left(r / a_{p}\right)$ and fractal dimensions (D) formed in the presence and absence of significant interparticle repulsion (i.e. slow and fast aggregation) are shown in Table 3. In all cases we have assumed that the permeability of the cake produced from aggregates formed slowly (in the presence of a repulsion barrier) is controlled by the smaller cohor of aggregates present. As can be seen from Figure 1a, these aggregates have sizes on the order of 0.4 to $1 \mu \mathrm{m}$. Ratios of aggregate to primary particle size $\left(\mathrm{r} / \mathrm{a}_{\mathrm{p}}\right)$ of either 10 (Cases 1 and 4$), 5$ (Case 2$)$ or 20 (Case 3) have thus been considered as possibly being representative of these slowly formed aggregates. Larger particles are also present but it is likely that the smaller aggregates would deposit preferentially given their insensitivity to back-transport processes. Aggregates formed rapidly assume an average size in the range 3 to $8 \mu \mathrm{m}$ (Figure 1b). Two possibilities have thus been examined, one in which aggregates are 100 times the size of the primary particles (Cases 1,2 and 3 ) and one in which aggregates are 50 times the size of primary particles (Case 4). We have also assumed that agoregates once deposited in the cake retain similar fractal dimensions to that measured in suspension. While compaction effects may well induce structural change, we have assumed a fractal dimension of 2.4 for aggregates formed in the presence of a repulsion barrier and either 2.2, 2.0 or 1.8 for more rapidly formed aggregates (recall that fractal dimensions of 2.35 and 


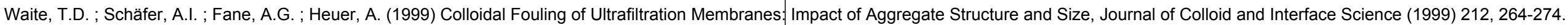
doi:10.1006/jcis.1998.6040

2.20 were measured by small angle light scattering for aggregates formed slowly and rapidly respectively).

It is clear from the results of calculations presented in Table 3 that both aggregate size and structure have a substantial effect on ease of fluid flow through the (assumed) fractal aggregates making up the cake. Aggregates characterised by Case $4 \mathrm{~A}(\mathrm{r}=0.7 \mu \mathrm{m}$ and $\mathrm{D}=2.4$ for slowly formed aggregates and $\mathrm{r}=3.5 \mu \mathrm{m}$ and $\mathrm{D}=2.2$ for rapidly formed aggregates) are considered most similar to the hematite assemblages investigated here and are estimated to exhibit an approximately order of magnitude decrease in specific cake resistance on change from slow to rapid aggregation similar to that found in this study.

Use of a modified Carman-Kozeny equation may not be the best way to account for effects of aggregate structure on cake permeability. Indeed, Veerapeni and Wiesner (5) have examined various formulations for describing the hydrodynamics of flow through fractal aggregates and show significant departure from experiment (and the predictions of other models) at high porosities when using the Carman-Kozeny formulation. Thus, both the method of accounting for the effect of fractal structure on aggregate permeability and (perhaps more importantly) the extent of retention of fracta structure of aggregates once deposited as a cake require further attention. However, the results presented here do suggest some retention of structure effects imbued through coagulation cond once aggregates are deposited as a cake and suggest that control of cake permeability via control of coagulation kinetics is an avenue worthy of further investigation.

\section{SUMMARY}

Cakes formed on ultrafiltration membranes as a result of collection of hematite aggregates generated rapidly in stirred suspension (in the absence of a repulsion barrier) exhibit a similar rate of cake accumulation as those formed slowly (in the presence of a repulsion barrier) but possess specific resistances that are an order of magnitude lower. This dramatic difference in cake resistance is considered to arise from the size and fractal properties of the hematite assemblages. The porosity of these assemblages will be influenced both by the fractal dimensions of the aggregates and by their size relative to primary particle size (since, for fractal aggregates, porosity increases as the size of the aggregate increases). The size and strength of aggregates are also important determinants of the relative effects of permeation drag, shear induced diffusion and inertial lift and result, in the studies reported here, in relatively similar rates of particle deposition for both rapidly and slowly formed aggregates.

While compaction effects may act to minimise some of the differences, it appears likely that the differences in size and fractal properties are induced by the kinetics of aggregation of hematite particles in suspension. Slowly formed aggregates possess a cohort of sub-micron sized aggregates of relatively high fractal dimension which form a reasonably impermeable cake while rapidly formed aggregates are generally of larger size and lower fractal dimension and thus create a substantially more permeable cake.

While the Carman-Kozeny equation is recognised to possess some weaknesses, particularly for cakes of high porosity, it does appear to provide a reasonable description of the proportional differences in specific resistances that might be expected for cakes formed from aggregates of differing size and fractal dimension. The results presented here suggest that control of cake permeability via control of coagulation kinetics is an avenue worthy of further investigation though the nature and extent of compaction effects in modifying the fractal properties of aggregates generated in suspension requires further attention.

\section{ACKNOWLEDGEMENTS} Professor Linkwitz from Stuttgarter Studentenwerk e.V. is acknowledged for supplying a partial
scholarship to A. Heuer and the German Academic Exchange Service (DAAD) and the CRC for scholarship to A. Heuer and the German Academic Exchange Service (DAAD) and the CRC for
Water Quality and Treatment are thanked for providing financial support to A. Schäfer. The assistance of Ursula Schwicker in undertaking cake mass experiments is gratefully acknowledged as is material support from Millipore Australia.

\section{REFERENCES}

1. Mallevialle, J., Odendaal, P.E., and Wiesner, M.R., In Water Treatment Membrane Processes; Mallevialle, J., Odendaal, P.E., Wiesner, M.R., Eds; McGraw-Hill: New York, 1996; Chap. 1, pp. $1.1-1.10$.

2. Wiesner, M.R., and Aptel, P., In Water Treatment Membrane Processes; Mallevialle, J., Odendaal, P.E., Wiesner, M.R., Eds; McGraw-Hill: New York, 1996; Chap. 4, pp. 4.1 - 4.30.

3. Bowen, W.R., and Jenner, F., Adv. Colloid Interface Sci. 56, 141 (1995).

4. Carman, P.C., Trans. Inst. Chem. Eng. 16, 168 (1938).

5. Veerapaneni, S., and Wiesner, M.R., J. Colloid Interface Sci. 177, 45 (1996).

6. Coulson, J.M., Richardson, J.F., Backhurst, J.R., and Harker, J.H., In Chemical Engineering; Vol. Two: Unit Operations; $3^{\text {rd }}$ Edition, Pergamon Press: Oxford, 1978; Chap. 4, pp. 125-171.

7. Lin M.Y., Klein R., Lindsay H.M., Weitz D.A., Ball R.C., and Meakin P., J. Colloid Interface Sci. 137, 263 (1990).

8. Jiang, Q., and Logan, B.E., Environ. Sci. Technol. 25, 2031 (1991).

9. Wiesner, M.R., Wat. Res. 26, 379 (1992).

10. Jullien, R., and Botet, R., Aggregation and Fractal Aggregates; World Scientific: Singapore, 1987.

11. Lin, M.Y., Lindsay, H.M., Weitz, D.A., Ball, R.C., Klein, R., and Meakin, P., Nature 339, 360 (1989).

12. Klein, R., Weitz, D.A., Lin, M.Y., Lindsay, H.M., Ball, R.C., and Meakin, P., Proc. Colloid Polym. Sci. 81, 161 (1990).

13. Grace, H.P., Chem. Eng. Prog. 49, 303 (1953).

14. McDonogh, R.M., Fell, C.J.D., and Fane, A.G., J. Membrane Sci. 21, 285 (1984)

15. McDonogh, R.M., Fane, A.G., and Fell, C.J.D., J. Membrane Sci. 43, 69 (1989).

16. Wiesner, M.R., Clark, M..M., and Mallevialle, J., J. Environ. Eng. 115, 1 (1989).

17. Schmitz, P., Wandelt, B., Houi, D., and Hildenbrand, M., J. Membrane Sci. 84, 171 (1993).

18. Kim, K-J., Chen, V., and Fane, A.G., J. Colloid Interface Sci. 155, 347 (1993).

19. Bacchin, P., Aimar, P., and Sanchez, V., Amer. Inst. Chem. Eng. J. 41, 368 (1995).

20. Zhu, X., and Elimelech, M., J. Environ. Eng. 121, 884 (1995).

21. Bacchin, P., Aimar, P., and Sanchez, V., J. Membrane Sci. 115, 49 (1996).

22. Meagher, L., Klauber, C., and Pashley, R.M., Colloids Surfaces A 106, 63 (1996).

23. Zhu, X., and Elimelech, M., Environ. Sci. Technol. 31, 3654 (1997).

24. Khatib, K., Rose, J., Barres, O., Stone, W., Bottero, J-Y., and Anselme, C., J. Membrane Sci. 130, 53 (1997).

25. Amal R., Raper J.A., and Waite T.D., J. Colloid Interface Sci. 140, 158 (1990).

26. Zhang, J., and Buffle, J., Colloids Surfaces A 107, 175 (1996).

27. Bushell, G.C., Amal, R., and Raper, J.A., Physica A 233, 659 (1996)

28. Matijevic E., and Scheiner P., J. Colloid Interface Sci. 63, 509 (1978)

29. Averett, R.C., Leenheer, J.A., McKnight, D.M., and Thorn, K.A., Humic Substances in the Suwannee River, Georgia: Interactions, Properties and Proposed Structures; U.S. Geological Survey Open File Report 87-557, 1989. 


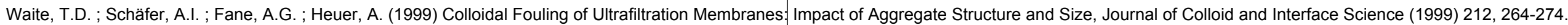
doi:10.1006/jcis.1998.6040

30. Schmidt, P.W., In The Fractal Approach to Heterogeneous Chemistry: Surfaces, Colloids, Polymers; Avnir, D., Ed.; Wiley: New York, 1989, Chap. 2.2, pp. 67-79.

31. Hiemenz, P.C., and Rajagopalan, R., Principles of Colloid and Surface Chemistry; Third Edition, Marcel Dekker: New York, 1997, Chap. 5, pp. 193-247.

32. Jung, S-J., Amal, R., and Raper, J.A., Part. Part. Syst. Charact. 12, 274 (1995)

33. Amal, R., Coury, J.R., Raper, J.A., Walsh, W.P., and Waite, T.D., Coll. Surf. 46, 1 (1990).

34. Sposito, G., Colloids Surfaces A 120, 101 (1997)

35. Cheryan, M., Ultrafiltration Handbook; Technomic Publishing Company: New York, 1986

36. Amal, R. Ph.D. Dissertation, University of New South Wales, Sydney, Australia, 1991.

37. Amal, R., Raper, J.A., and Waite, T.D., J. Colloid Interface Sci. 151, 244 (1992).

38. Muhle, K., In Coagulation and Flocculation: Theory and Applications; Dobias, B., Ed.; Marcel Dekker: New York, 1993, Chap. 8, pp. 355-390.

39. Schafer, M., Hofken, M., and Durst, F., Trans. Inst. Chem. Eng. 75(A), 729 (1997).

40. Dong, L., Johansen, T., and Engh, T.A., Chem. Eng. Sci. 49, 549 (1994).

41. Ciofalo, M., Brucato, A., Grisafi, F., and Torraca, N., Chem. Eng. Sci. 51, 3557 (1996).

42. Spicer, P.T., and Pratsinis, S.E., Wat. Res. 30, 1049 (1996).

43. Parker, D.S., Kaufman, W.J., and Jenkins, D., ASCE J. San. Eng. Div., 98, 79 (1972).

44. Oles, V.J., J. Colloid Interface Sci. 154, 2 (1992).

45. Lahoussine-Turcard, V., Wiessner, M.R., and Bottero, J-Y., J. Membrane Sci. 52, 173 (1990).

46. Belfort, G., Davis, R.H., and Zydney, A.L., J. Membrane Sci. 96, 1 (1994).

\section{TABLES}

Table 1. Initial flux (J), flux after passage of $28 \mathrm{~L}$ of permeate $(J)$ and membrane $\left(R_{m}\right)$ and cake $\left(R_{c}\right)$ resistances for the various solution compositions used in studies reported in this paper. (Note: Pure water flux $=1637 \pm 47 \mathrm{~L} \cdot \mathrm{m}^{-2} \cdot \mathrm{h}^{-1}$ ).

\begin{tabular}{|c|c|c|c|c|c|}
\hline $\begin{array}{c}\text { Solution } \\
\text { Composition }\end{array}$ & $\begin{array}{c}\text { Initial } \\
\text { Flux } \\
{\left[\mathrm{Lm}^{-2} \mathrm{~h}^{-1}\right]}\end{array}$ & $\begin{array}{c}\text { Flux } \\
(2.8 \mathrm{~L}) \\
{\left[\mathrm{Lm}^{-2} \mathrm{~h}^{-1}\right]}\end{array}$ & $\begin{array}{c}\text { Membrane } \\
\text { Resistance } \\
{\left[10^{10} \mathrm{~m}^{-1}\right]}\end{array}$ & $\begin{array}{c}\text { Total } \\
\text { Resistance } \\
{\left[10^{10} \mathrm{~m}^{-1}\right]}\end{array}$ & $\begin{array}{c}\text { Cake } \\
\text { Resistance } \\
{\left[10^{10} \mathrm{~m}^{-1}\right]}\end{array}$ \\
\hline$[\mathrm{KCl}], \mathrm{mM}$ & 1523 & 690 & 0.71 & 1.56 & 0.85 \\
0 & 1543 & 609 & 0.70 & 1.77 & 1.07 \\
10 & 1444 & 578 & 0.75 & 1.86 & 1.12 \\
10 & 1306 & 574 & 0.82 & 1.88 & 1.05 \\
20 & 1642 & 613 & 0.66 & 1.76 & 1.10 \\
20 & 1437 & 679 & 0.75 & 1.59 & 0.84 \\
40 & 1701 & 780 & 0.63 & 1.38 & 0.75 \\
70 & 1800 & 1546 & 0.60 & 0.70 & 0.099 \\
80 & 1741 & 1543 & 0.62 & 0.70 & 0.079 \\
100 & 1820 & 1681 & 0.59 & 0.64 & 0.049 \\
100 & 1662 & 1503 & 0.65 & 0.72 & 0.068 \\
150 & 1830 & 1609 & 0.59 & 0.67 & 0.081 \\
{$[\mathrm{NaCl}], \mathrm{mM}$} & & & & & \\
20 & 1622 & 646 & 0.66 & 1.67 & 1.00 \\
40 & 1609 & 673 & 0.67 & 1.60 & 0.93 \\
60 & 1543 & 1278 & 0.70 & 0.84 & 0.14 \\
80 & 1563 & 1444 & 0.69 & 0.75 & 0.057 \\
{$\left[\mathrm{CaCl} l_{2}\right], \mathrm{mM}$} & & & & & \\
20 & 1543 & 742 & 0.70 & 1.45 & 0.75 \\
40 & 1602 & 1456 & 0.67 & 0.74 & 0.068 \\
60 & 1642 & 1424 & 0.66 & 0.76 & 0.10 \\
80 & 1662 & 1495 & 0.65 & 0.72 & 0.072 \\
$\mathrm{Mean}( \pm \mathrm{std} . \mathrm{err})$. & $1612 \pm 30$ & & $0.67 \pm 0.01$ & & \\
{$[\mathrm{FA}], \mathrm{mg} / \mathrm{L}$} & & & & & \\
0 & 1523 & 690 & 0.71 & 1.56 & 0.85 \\
1 & 1563 & 1230 & 0.69 & 0.88 & 0.19 \\
2 & 1484 & 1125 & 0.73 & 0.96 & 0.23 \\
5 & 1530 & 580 & 0.70 & 1.85 & 1.15 \\
10 & 1780 & 571 & 0.60 & 1.88 & 1.28 \\
\hline & & & & & \\
\hline
\end{tabular}




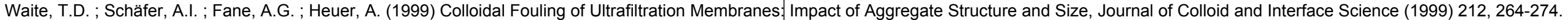
doi:10.1006/jcis.1998.6040

Table 2. Specific cake resistances for $20 \mathrm{mM}$ and $100 \mathrm{mM} \mathrm{KCl}$ studies for permeate volumes of 1.0, 1.5 and 2.0 L. Cake masses as reported in Figure 5.

\begin{tabular}{|c|c|c|c|c|c|c|c|}
\hline $\begin{array}{c}\mathrm{KCl} \\
\text { Conc. } \\
{[\mathrm{mM}]}\end{array}$ & $\begin{array}{c}\text { Permeate } \\
\text { Volume } \\
{[\mathrm{mL}]}\end{array}$ & $\begin{array}{c}\text { Cake } \\
\text { Mass } \\
{[\mathrm{mg}]}\end{array}$ & $\begin{array}{c}\text { Flux } \\
{\left[\mathrm{Lm}^{-2} \mathrm{~h}^{-1}\right]}\end{array}$ & $\begin{array}{c}\text { Flux } \\
\text { Ratio } \\
{[-]}\end{array}$ & $\begin{array}{c}\text { Membrane } \\
\text { Resistance } \\
{\left[10^{10} \mathrm{~m}^{-1}\right]}\end{array}$ & $\begin{array}{c}\text { Cake } \\
\text { Resistance } \\
{\left[10^{10} \mathrm{~m}^{-1}\right]}\end{array}$ & $\begin{array}{c}\text { Specific } \\
\text { Resistance } \\
{\left[10^{10} \mathrm{~m}_{\mathrm{g}} \mathrm{g}^{-1}\right]}\end{array}$ \\
\hline 20 & 1000 & 7 & 901 & 0.7 & 0.83 & 0.37 & 1.07 \\
20 & 1500 & 9 & 783 & 0.6 & 0.83 & 0.55 & 1.24 \\
20 & 2000 & 11.5 & 708 & 0.53 & 0.83 & 0.70 & 1.23 \\
100 & 1000 & 5 & 1745 & 0.96 & 0.59 & 0.025 & 0.103 \\
100 & 1500 & 7 & 1738 & 0.95 & 0.59 & 0.028 & 0.081 \\
100 & 2000 & 8 & 1715 & 0.94 & 0.59 & 0.036 & 0.092 \\
\hline
\end{tabular}

Table 3. Ratio of specific cake resistances $(\alpha)$ calculated using the Carman-Kozeny equation resulting from aggregates of various size and structure formed in the presence and absence of significant interparticle repulsion (slow and rapid aggregation).

\begin{tabular}{|c|c|c|c|c|c|c|}
\hline Case & $\begin{array}{c}\text { Aggregation } \\
\text { Rate }\end{array}$ & $\mathrm{r} / \mathrm{a}_{\mathrm{p}}$ & $\mathrm{D}$ & $\varepsilon^{1}$ & $\begin{array}{c}\alpha^{2} \\
{\left[10^{10} \mathrm{~m} \cdot \mathrm{g}^{-1}\right]}\end{array}$ & $\frac{\alpha^{\text {slow }}}{\alpha^{\text {rapid }}}$ \\
\hline 1 & Slow & 10 & 2.4 & 0.749 & 0.42 & \\
A & Rapid & 100 & 2.2 & 0.975 & 0.019 & 22.1 \\
B & Rapid & 100 & 2.0 & 0.990 & 0.007 & 59.8 \\
C & Rapid & 100 & 1.8 & 0.996 & 0.003 & 149.5 \\
\hline 2 & Slow & 5 & 2.4 & 0.619 & 1.13 & \\
A & Rapid & 100 & 2.2 & 0.975 & 0.019 & 59.5 \\
B & Rapid & 100 & 2.0 & 0.990 & 0.007 & 160.6 \\
C & Rapid & 100 & 1.8 & 0.996 & 0.003 & 401.5 \\
\hline 3 & Slow & 20 & 2.4 & 0.834 & 0.20 & \\
A & Rapid & 100 & 2.2 & 0.975 & 0.019 & 10.6 \\
B & Rapid & 100 & 2.0 & 0.990 & 0.007 & 28.6 \\
C & Rapid & 100 & 1.8 & 0.996 & 0.003 & 71.5 \\
\hline 4 & Slow & 10 & 2.4 & 0.749 & 0.42 & \\
A & Rapid & 50 & 2.2 & 0.956 & 0.035 & 11.9 \\
B & Rapid & 50 & 2.0 & 0.980 & 0.015 & 28.1 \\
C & Rapid & 50 & 1.8 & 0.991 & 0.006 & 64.7 \\
\hline
\end{tabular}

$\varepsilon=1-\left(\mathrm{r} / \mathrm{a}_{\mathrm{p}}\right)^{\mathrm{D}}$ where $\mathrm{D}=$ fractal dimension

${ }^{2} \alpha=\mathrm{k}(1-\varepsilon) / \varepsilon^{3}$ where $\mathrm{k}=180 / \rho_{\mathrm{p}} \mathrm{d}_{\mathrm{p}}{ }^{2}\left(=7.07 \times 10^{9} \mathrm{~m} \cdot \mathrm{g}^{-1}\right.$ for $70 \mathrm{~nm}$ diameter hematite particles $)$ 


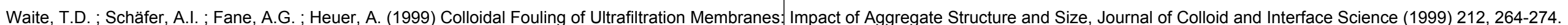
doi:10.1006/jcis.1998.6040

\section{FIGURE CAPTIONS}

FIG. 1. Volume based size distributions of hematite aggregates formed after 17 hours of slow stirring of hematite particles added to $\mathrm{pH} 3$ solutions containing a) $10 \mathrm{mM}$ and b) $100 \mathrm{mM} \mathrm{KCl}$ (stirrer speed $=220 \mathrm{rpm}$ )

FIG. 2. Results of small angle static light scattering studies of hematite aggregates formed after 17 hours of slow stirring of hematite particles added to $\mathrm{pH} 3$ solutions containing $10 \mathrm{mM}$ and $100 \mathrm{mM}$ $\mathrm{KCl}$ (stirrer speed $=220 \mathrm{rpm}$ ). Plots show scattered light intensity as a function of wave number $\mathrm{q}=$ $(4 \pi \mathrm{n} / \lambda) \sin (\theta / 2)$ where $\mathrm{n}$ is the refractive index of the medium, $\theta$ is the angle of scatter from the incident beam and $\lambda$ is the wavelength of the incident beam (a He-Ne laser with $\lambda=632.8 \mathrm{~nm}$ ). Linear fits to selected "power law" regions of the data are shown as is the resultant computed contribution to scattering by a cohort of small aggregates at high $\mathrm{q}$.

FIG. 3. Permeate flux (J) as a fraction of initial flux $\left(\mathrm{J}_{\mathrm{o}}\right)$ over the course of ultrafiltration of suspensions of hematite aggregates prepared and filtered at various $\mathrm{KCl}$ concentrations $\left(\left[\alpha-\mathrm{Fe}_{2} \mathrm{O}_{3}\right]=\right.$ $10 \mathrm{mg} / \mathrm{L}, \mathrm{pH}=3, \Delta \mathrm{p}=300 \mathrm{kPa}$, UF cell stirrer speed $=520 \mathrm{rpm}$ ).

FIG. 4. Cake resistance after filtration of $2.8 \mathrm{~L}$ of hematite suspension for different $\mathrm{KCl}$ concentrations $\left(\left[\alpha-\mathrm{Fe}_{2} \mathrm{O}_{3}\right]=10 \mathrm{mg} / \mathrm{L}, \mathrm{pH}=3, \Delta \mathrm{p}=300 \mathrm{kPa}\right.$, stirrer speed $\left.=520 \mathrm{rpm}\right)$. The critical coagulation concentration at which aggregation is considered to change from reaction limitation to transport limitation is also shown.

FIG. 5. Mass of cake formed on membrane filtration of hematite suspensions formed (and suspended) in $20 \mathrm{mM}$ and $100 \mathrm{mM} \mathrm{KCl}$. Cake masses deduced from both direct weight measurement and from amount of $\alpha-\mathrm{Fe}_{2} \mathrm{O}_{3}$ retained (as determined by iron analysis) are shown ([ $\alpha-$ $\left.\mathrm{Fe}_{2} \mathrm{O}_{3}\right]=10 \mathrm{mg} / \mathrm{L}, \mathrm{pH}=3, \Delta \mathrm{p}=300 \mathrm{kPa}$, UF cell stirrer speed $=520 \mathrm{rpm}$ )

FIG. 6. Permeate flux $(\mathrm{J})$ as a fraction of initial flux $\left(\mathrm{J}_{\mathrm{o}}\right)$ over the course of ultrafiltration of suspensions of hematite aggregates prepared and filtered at various $\mathrm{CaCl}_{2}$ concentrations $\left(\left[\alpha-\mathrm{Fe}_{2} \mathrm{O}_{3}\right]\right.$ $=10 \mathrm{mg} / \mathrm{L}, \mathrm{pH}=3, \Delta \mathrm{p}=300 \mathrm{kPa}$, UF cell stirrer speed $=520 \mathrm{rpm}$ ).

FIG. 7. Cake resistance after filtration of $2.8 \mathrm{~L}$ of hematite suspension for different $\mathrm{CaCl}_{2}$ concentrations $\left(\left[\alpha-\mathrm{Fe}_{2} \mathrm{O}_{3}\right]=10 \mathrm{mg} / \mathrm{L}, \mathrm{pH}=3, \Delta \mathrm{p}=300 \mathrm{kPa}\right.$, UF cell stirrer speed $\left.=520 \mathrm{rpm}\right)$. The critical coagulation concentration at which aggregation is considered to change from reaction limitation to transport limitation is also shown.

FIG. 8. Permeate flux (J) as a fraction of initial flux $\left(\mathrm{J}_{\mathrm{O}}\right)$ over the course of ultrafiltration of suspensions of hematite aggregates prepared and filtered at various $\mathrm{pH}\left(\left[\alpha-\mathrm{Fe}_{2} \mathrm{O}_{3}\right]=10 \mathrm{mg} / \mathrm{L},[\mathrm{KCl}]\right.$ $=40 \mathrm{mM}, \Delta \mathrm{p}=300 \mathrm{kPa}$, UF cell stirrer speed $=520 \mathrm{rpm}$ ).

FIG. 9. Permeate flux $(\mathrm{J})$ as a fraction of initial flux $\left(\mathrm{J}_{\mathrm{o}}\right)$ over the course of ultrafiltration of suspensions of hematite aggregates prepared and filtered in the presence of various concentrations of fulvic acid $\left(\left[\alpha-\mathrm{Fe}_{2} \mathrm{O}_{3}\right]=10 \mathrm{mg} / \mathrm{L},[\mathrm{KCl}]=40 \mathrm{mM}, \mathrm{pH}=3, \Delta \mathrm{p}=300 \mathrm{kPa}\right.$, UF cell stirrer speed = $520 \mathrm{rpm})$

FIG. 10. a) Zeta potential of hematite particles at $\mathrm{pH} 3$ in the presence of various concentrations of fulvic acid, and b) Cake resistance after filtration of $2.8 \mathrm{~L}$ of hematite suspension for different fulvic acid concentrations $\left(\left[\alpha-\mathrm{Fe}_{2} \mathrm{O}_{3}\right]=10 \mathrm{mg} / \mathrm{L},[\mathrm{KCl}]=40 \mathrm{mM}, \mathrm{pH}=3, \Delta \mathrm{p}=300 \mathrm{kPa}\right.$, UF cell stirrer speed $=520 \mathrm{rpm})$
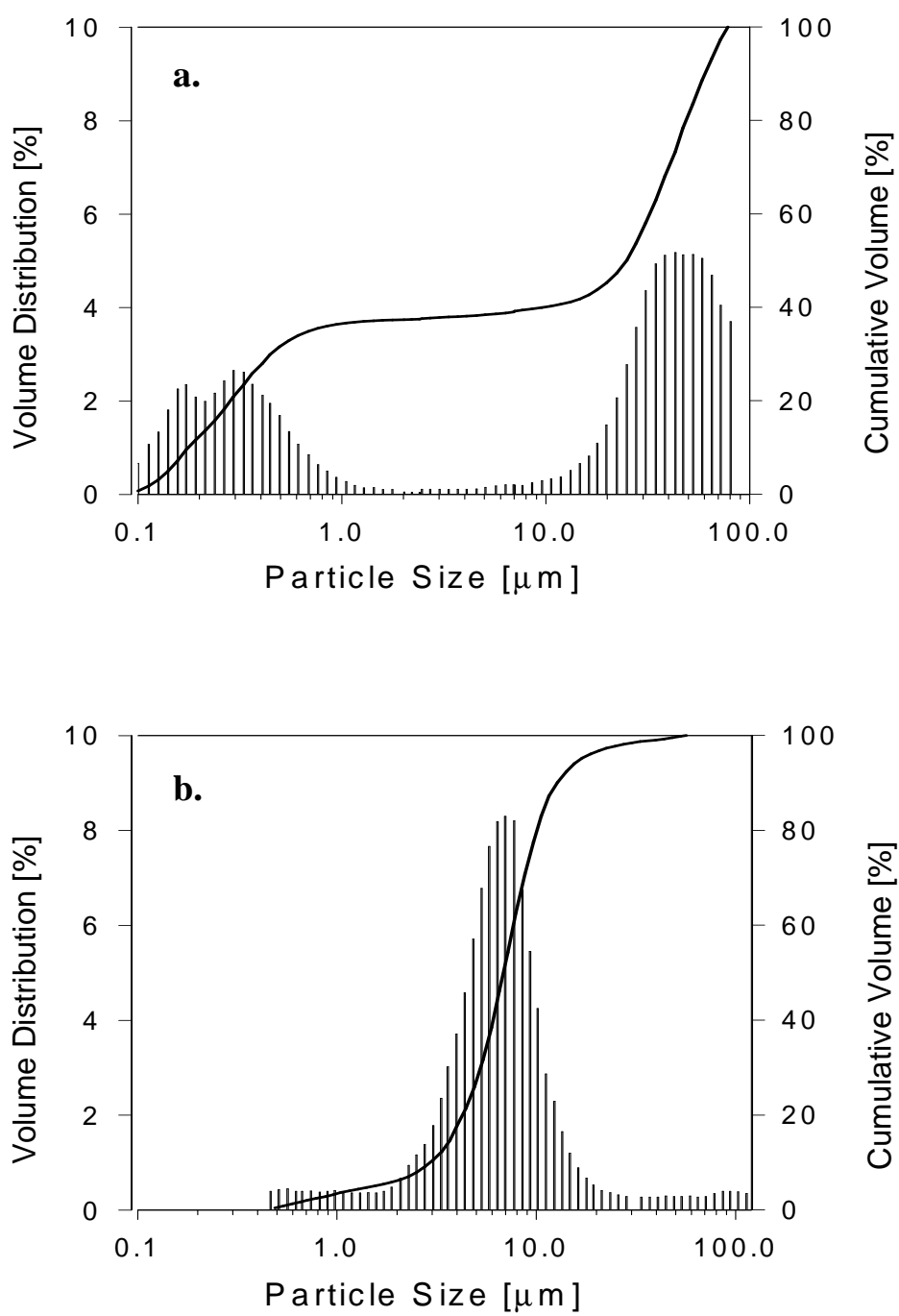


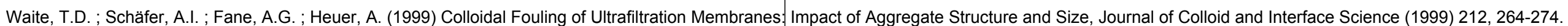
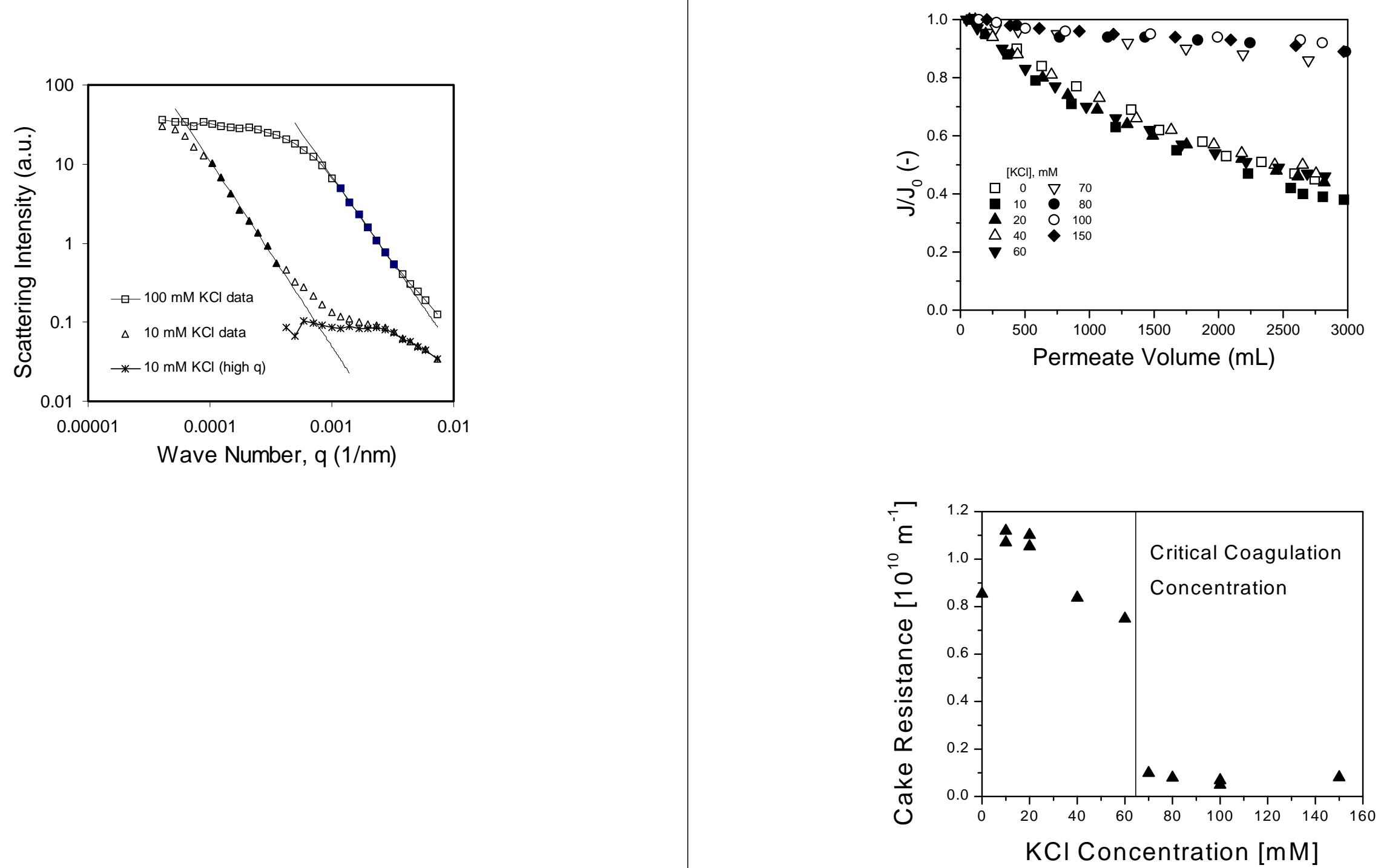

Figure 4 


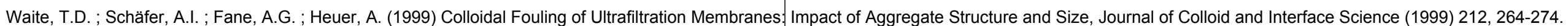
doi:10.1006/jcis. 1998.6040
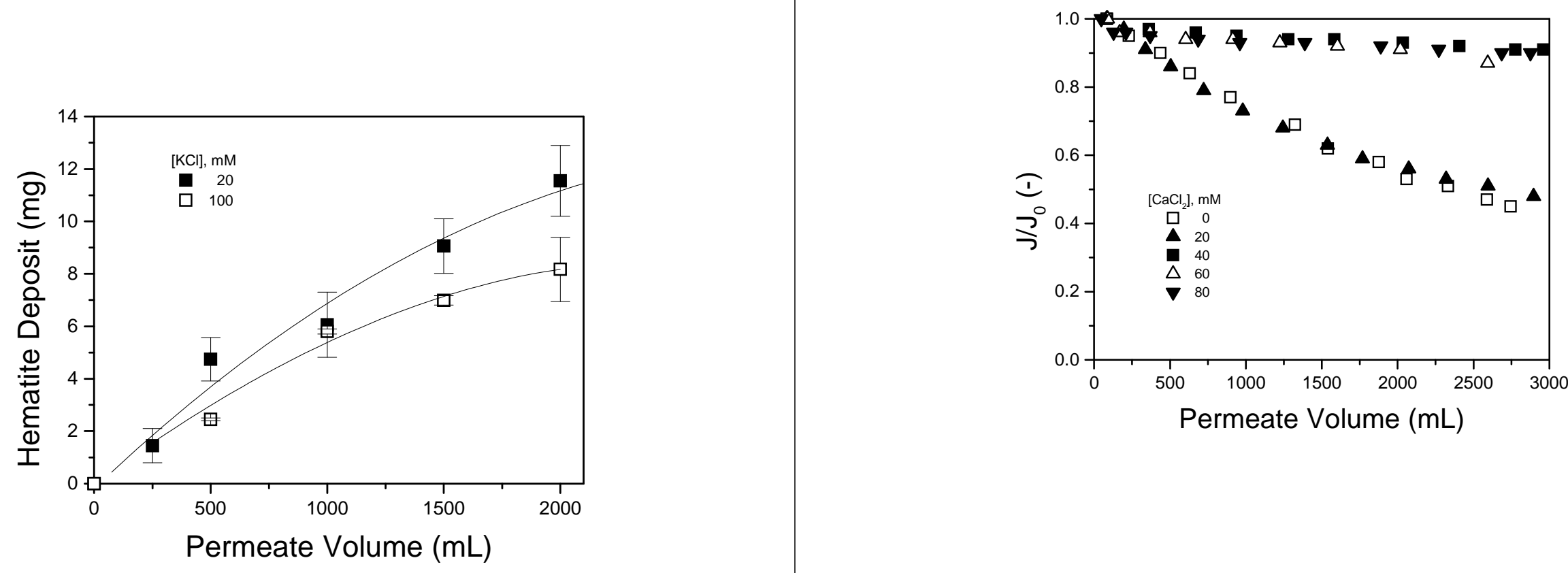

Figure 7

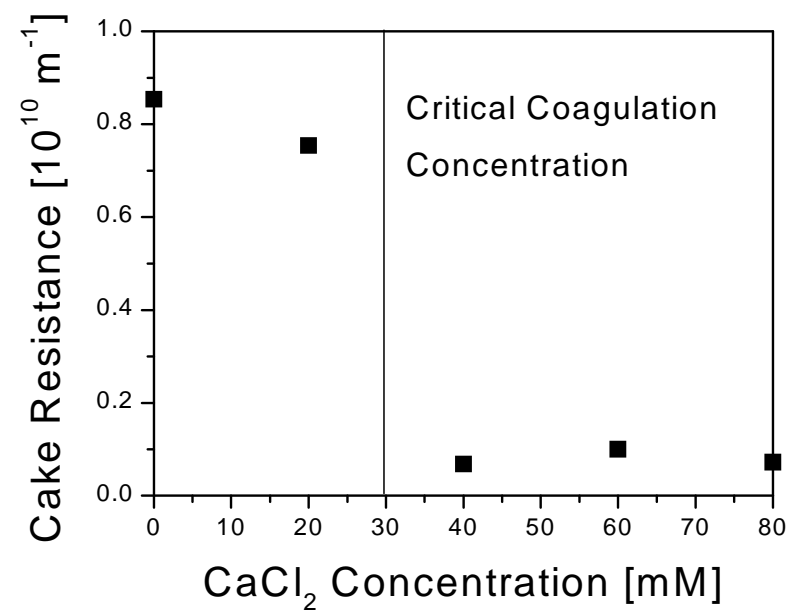




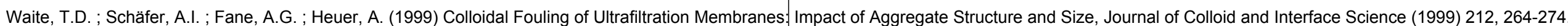
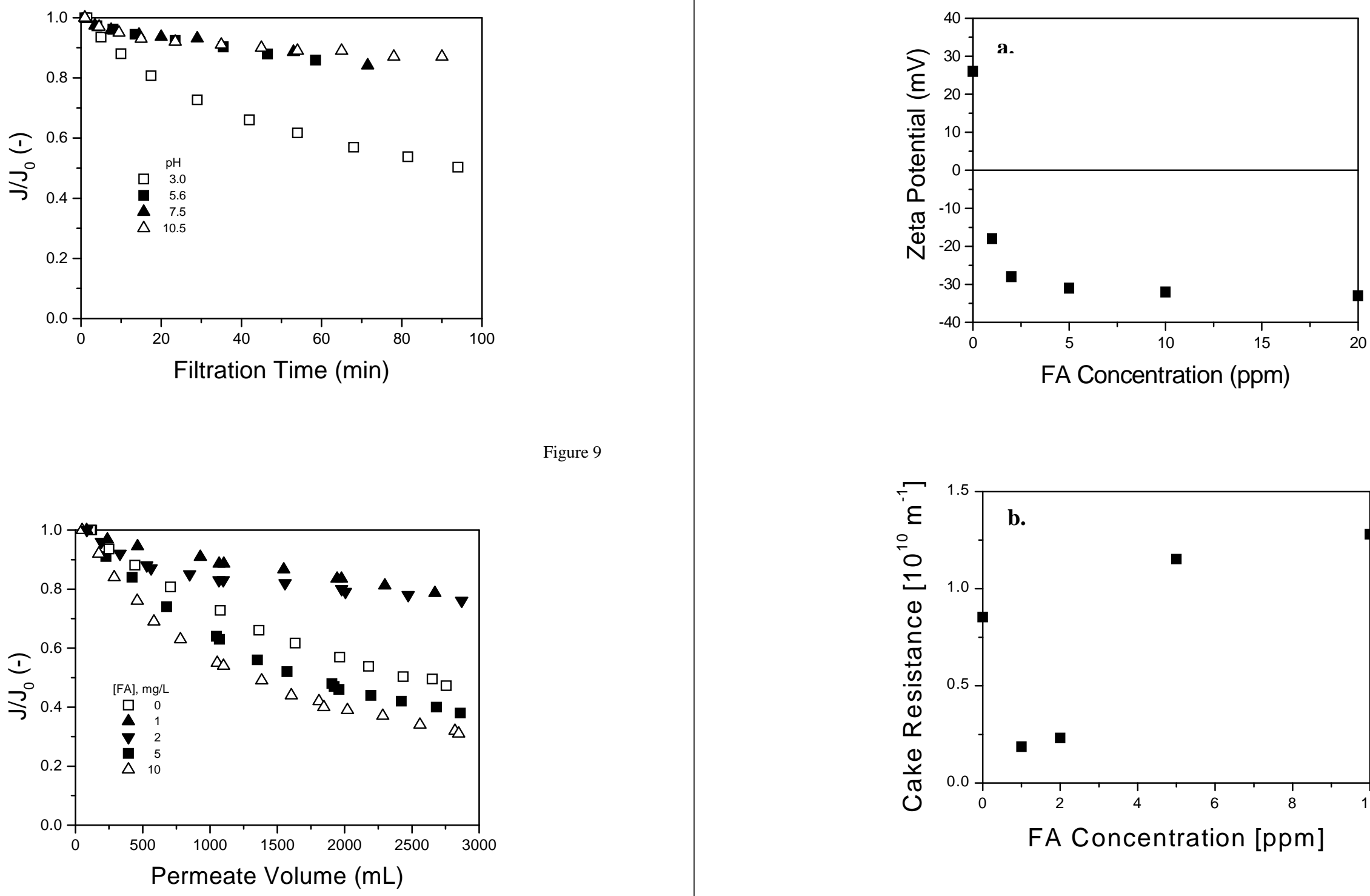

Figure 9

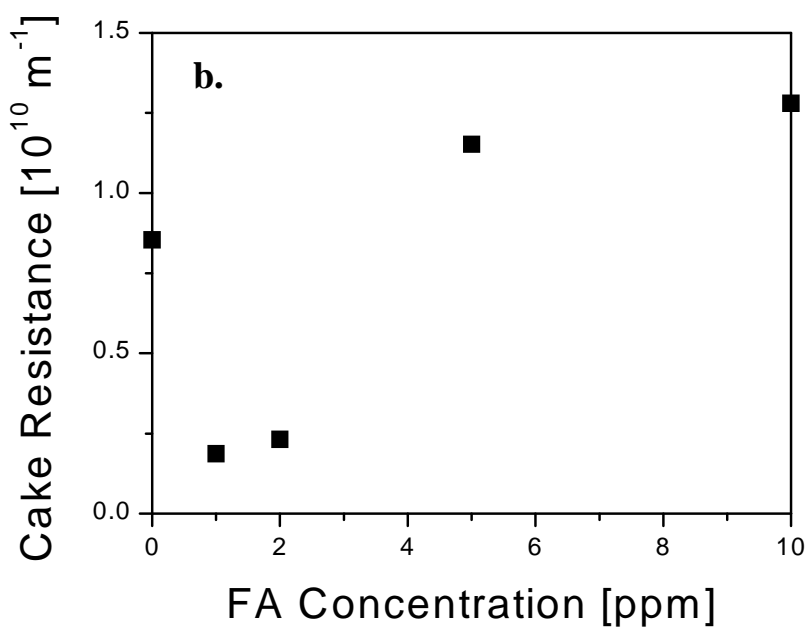

